Article

\title{
The Impact of Powering an Engine with Fuels from Renewable Energy Sources including its Software Modification on a Drive Unit Performance Parameters
}

\author{
Marietta Markiewicz and Łukasz Muślewski *(D) \\ Faculty of Mechanical Engineering, UTP University of Science and Technology, 85-796 Bydgoszcz, Poland; \\ marmar000@utp.edu.pl \\ * Correspondence: lukasz.muslewski@utp.edu.pl
}

Received: 7 October 2019; Accepted: 15 November 2019; Published: 21 November 2019

\begin{abstract}
The application of fuels from renewable energy sources for combustion engine powering involves a great demand for this kind of energy while its production infrastructure remains underdeveloped. The use of this kind of fuel is supposed to reduce the emission of greenhouse gases and the depletion of natural resources and to increase the share of renewable energy sources in total energy consumption and thus support sustainable development in Europe. This study presents the results of research on selected performance parameters of transport by internal combustion engines including: power, torque, the emission of sound generated by the engine, the content of exhaust components (oxygen $\mathrm{O}_{2}$, carbon monoxide $\mathrm{CO}$, carbon dioxide $\mathrm{CO}_{2}$, nitrogen dioxide $\mathrm{NO}_{2}$ ), and the content of particulate matter (PM) in exhaust emission. Three self-ignition engines were tested. The fuel injection controllers of the tested internal combustion engines were additionally adjusted by increasing the fuel dose and the load of air. The material used in the tests were mixtures of diesel oil and fatty acid methyl esters of different concentration. A statistical analysis was performed based of the results. The purpose of the work was to develop a resulting model for assessing the operation of engines fueled with biofuel and diesel mixtures while changing the vehicle's computer software. A computer simulation algorithm was also developed for the needs of the tests which was used to prognose the state of the test results for variable input parameters.
\end{abstract}

Keywords: renewable energy sources; alternative fuels; biofuels; self-ignition engines transport means

\section{Introduction}

The use of fuels from renewable energy sources for internal combustion engine powering is caused by a high demand for fuel and the depletion natural resources. Structural solutions of combustion engines enable their modernization to implement solutions suitable for the use of fuels of plant origin [1]. The first argument in favor of biofuels is the exhaustibility of fossil fuels and the necessity to preserve natural resources for future generations. Crude oil is the number one natural energy source and according to current predictions this situation will persist until 2030. Renewable fuels of vegetable origin include rapeseed oil, soybean oil, sunflower oil, peanut oil, and animal fats [2]. For technical, economic, constructional, and technological reasons, rapeseed oil is the most commonly used, and it is subjected to a chemical processing process in order to use it to supply ZS (compression ignition engine) devices [3-5]. Scientific research conducted in many research centers has revealed that diesel oil can be mixed with plant oils or substituted by them [6-10]. Renewable fuels used for self-ignition combustion engine powering include: plant oils (rape, soya, sunflower, peanut oils), animal fats, biogas (produced from fruit and vegetable waste and meat waste) [11], post pyrolytic oil (from used car tires) [12], municipal and sewage waste, agricultural waste, post frying oils [13-15], and micro 
algae $[16,17]$. The above listed substances used for engine powering are divided into three generations of biofuels. The application of biofuels as an alternative fuel or an additive to diesel oil protects the natural environment and is a new solution in the transportation sector. Biofuels of the first generation, especially transesterificated rape oils (fatty acid methyl esters) are still the most widespread because of their availability and low treatment costs $[1,6-10]$.

The results of research conducted in numerous research and industrial centers worldwide confirm that physical -chemical properties of fatty acid methyl esters are similar to the properties of diesel oil which makes them number one biofuel $[18,19]$. Biodiesel is produced from renewable sources and is considered an alternative fuel for self-ignition engines. In contrast to a common diesel oil, biodiesel is a biodegradable and nontoxic fuel. The application of biodiesel contributes to a significant reduction in the emission of harmful substances into the atmosphere [20-23]. It can always be used where diesel oil is used [24]. Pure fatty acid methyl esters FAME (fatty acid methyl esters) and their mixtures with diesel oil are referred to as biodiesel. Depending on the applied proportions, the mixtures of diesel oil and fatty acid methyl esters (FAME) are denoted as, e.g., B100, B80, and B20. Additionally, the lubrication characteristics of biodiesel are better than those of a traditional oil which significantly prolongs the engine life $[25,26]$.

The advisability of the application of fuels from renewable sources is targeted at internal combustion engines. The literature provides some results of research on engine operation efficiency, fuel consumption, and exhaust emission components, including PM, for an internal combustion engine powered with biofuel. Many researchers have been involved in research on fuel consumption [27,28]. The authors have noted an increase in fuel demand for self-ignition engines powered with mixtures of diesel oil and fatty acid methyl esters [29-31]. The fuel consumption of an engine for a mixture of 35\% fatty acid methyl esters with a diesel oil increases by about $18 \%$ as compared to pure diesel oil. [31]. Changes in unit fuel consumption (fuel consumption has the dimension volume of petroleum per length or length per volume of petroleum) are observable already for a $5 \%$ additive of biocomponent [32,33]. Numerical quantities characterizing the combustion engine operation which are used for assessment and comparison are determinants of combustion engines. An analysis of these quantities provides detailed information on the combustion engine characteristics. The most common indicators of the combustion engine operation are power, torque, fuel consumption, and exhaust emission components. An analysis of literature shows an increase in the values of the engine performance parameters and lower power drops as compared to diesel oil, depending on the combustion system and characteristics of the injection system [9,34-39]. Powering combustion engines with biofuels also contributes to a reduction in pollution caused by exhaust emission components such as carbon monoxides, hydrocarbons, and PM [28,40-49]. Nitrogen oxides are an exception to this however as their value increases by several percent as compared to pure diesel oil [42,50-52].

The literature studies and the authors' own research have allowed us to identify eight performance parameters which were evaluated in terms of the quality of the research objects operation. The analyzed performance parameters were selected due to their significant impact on the considered objects functioning and their influence on the natural environment. The goal of this study was to determine an optimal adjustment of the fuel injection controller to different fuel mixtures due to characteristics of the internal combustion engine performance parameters. The use of biofuels, while maintaining high engine performance, leads to the use of the potential of compression-ignition engines while maintaining low emissions of environmentally hazardous components, which leads to the sustainable development of the economy and the environment.

\section{Materials and Methods}

The experiment was conducted in order to determine performance parameters for engines with self-ignition for each mixture of diesel oil and fatty acid methyl esters with established settings of the internal combustion engine. The experiment was intentionally interfered with in order to obtain the required information. While planning the experiment the following rules were applied: 
- the experiment goal and subject were precisely defined,

- physical conditions of the experiment were specified,

- variability factors and range necessary to discover cause and effect relations were established,

- the experiment model was developed,

- the experiment course - measurement rules and sample population size were defined, and

- the rules for the experiment results analysis were provided.

The study objects were self-ignition engines, which were selected due to their widespread application in road transport. Three identical types of vehicles were tested. The technical characteristics of the engines tested are presented in Table 1.

Table 1. Technical data of a power unit.

\begin{tabular}{cc}
\hline swept capacity $\left[\mathrm{cm}^{3}\right]$ & 1560 \\
engine power [KM]/[kW] & $102 / 78$ \\
maximum turning moment [Nm] & 238 \\
number of cylinders & 4 \\
diameter of a cylinder [mm] & 73 \\
piston stroke [mm] & 88.3 \\
number of valves & 16 \\
type of injection & direct, Common Rail \\
Supercharging & turbocompressor \\
filter of particulate solids & does not have \\
\hline
\end{tabular}

The power of each engine was $81 \mathrm{~kW}$ for $4000 \mathrm{RPM}$, and the maximum torque was $240 \mathrm{Nm}$ with 1700 RPM. Characteristics of factory settings of one of the test engines is presented in Figure 1.

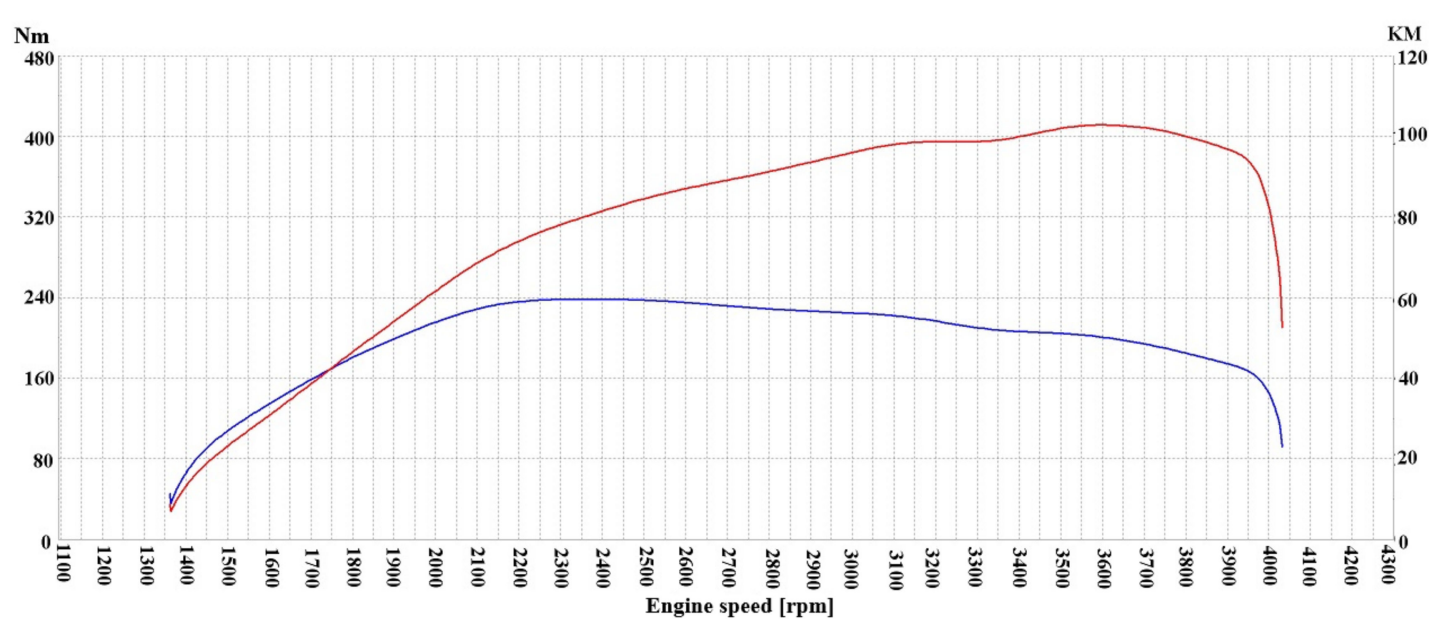

Figure 1. Characteristics of an exemplary test engine.

The research object supply system was adjusted to enable a non-invasive fuel exchange. These included adjustment of:

- the fuel supply system,

- the installation of an additional fuel tank, and

- computer software.

The modifications did not directly affect the engine structure but the fixtures and the computer software. Modifications of the fuel supply system involved fixing an additional tank with the simultaneous disconnection of fluid flow from the original tank. The fuel supply system was connected from the additional tank directly to the internal combustion engine. The fuel pump sucked the fuel 
mixture which passed through an initial filter. Then, the fuel was forced into a purification filter. From the fine purification filter the mixture was supplied to a supply chamber of a high-pressure system and forced down via an injection system to electromagnetic injectors fixed on the head. The electronically controlled injector adjusted the start of the injection and the fuel dose. The mixture was directly injected to the swirl chamber. The supplied mixture was sprayed within the cylinder working space a mixed with the sucked air. Standard filters designed for a given engine model were used. Fuel excess returned to the external fuel tank mounted with the use of a return fuel pipe. Following each fuel exchange, the engines were run for 10 minutes in order to remove the previous fuel residues from the fuel filter and the supply system. Injection parameters were changed for each type of fuel mixture.

Changes also involved adjusting the engine electronic system, by modifying the internal combustion engine manufacturer's computer software. The introduction of changes into the fuel injection controller was to determine whether and how the vehicle performance parameters change. Due to the specificity of the electronic system, it was necessary to disassemble the deck computer and introduce software changes on a special test stand (Figure 2). Prior to the introduction of changes in the computer software, a diagnostic measurement was performed to determine the possibilities and advisability of the engine parameter changes.

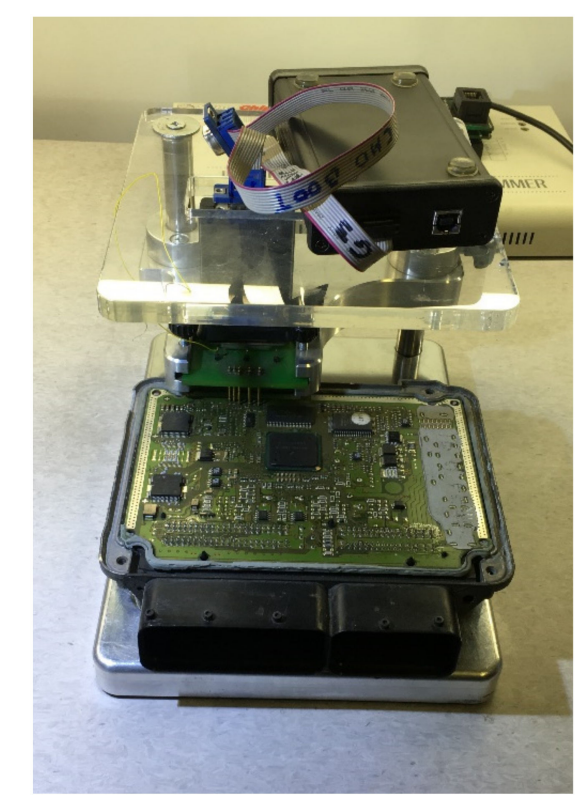

Figure 2. Stand for the vehicle engine computer software modification (fuel injection controller settings).

Adjustments of the fuel injection controller were performed according to a pre-determined experiment schedule. The modification of the vehicle software involved increasing the fuel dose and adding air load. The tests covered four settings which are presented in Table 2. Exemplary characteristics of the fuel injection are presented in Figure 3.

Table 2. Modification of the vehicle engine computer software (fuel injection controller settings).

\begin{tabular}{cc}
\hline Computer Software Modifications & Modification Number \\
\hline Factory settings & I \\
Fuel dose increased by $2 \%$ and air supply by $50 \mathrm{hPa}$ & II \\
Fuel dose increased by $4 \%$ and air supply by $50 \mathrm{hPa}$ & III \\
Fuel dose increased by $6 \%$ and air supply by $50 \mathrm{hPa}$ & IV \\
\hline
\end{tabular}




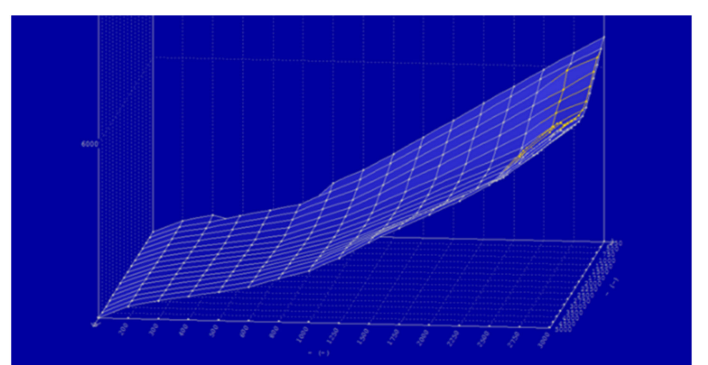

(a)

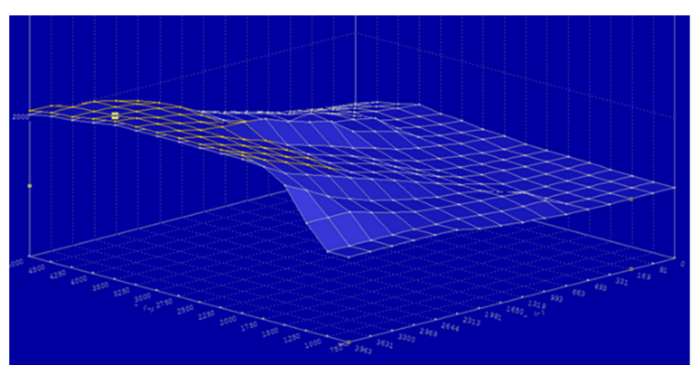

(b)

Figure 3. Fuel injection characteristics: (a) for fuel dose increased by $2 \%$ from the nominal value; (b) for air supply increased by $50 \mathrm{hPa}$ from the nominal value.

The tested internal combustion engines were supplied by mixtures of diesel oil and fatty acid methyl esters of different concentration. Diesel oil with no biocomponent additive was used as a model fuel (reference point) in the tests. The material used for the research, in addition to diesel, were vegetable oils subjected to the process of transesterification, i.e., the exchange of chemically bound glycerin in the triacylglycerol molecule for the added methyl alcohol in the presence of a basic or acid catalyst, which are commonly called biocomponents. The proportions of the mixtures and their designation are presented in Table 3.

Table 3. Proportions of the test mixtures.

\begin{tabular}{cc}
\hline Mixture Composition & Mixture Denotation \\
\hline Diesel oil & ON \\
$70 \%$ diesel oil 30\% fatty acid methyl esters & B30 \\
$50 \%$ diesel oil 50\% fatty acid methyl esters & B50 \\
\hline
\end{tabular}

Eight performance parameters (tested parameters) characterizing transport internal combustion engines were tested, namely power, torque, sound emission generated by the internal combustion engine, content of PM in exhaust emissions, and the composition of exhaust gases (oxygen, carbon monoxide, carbon dioxide, nitrogen dioxides). Each of the eight performance parameters were tested for a configuration mixture-fuel injection setting (12 configurations). The experimental program was performed according to the scheme presented in Figure 4.

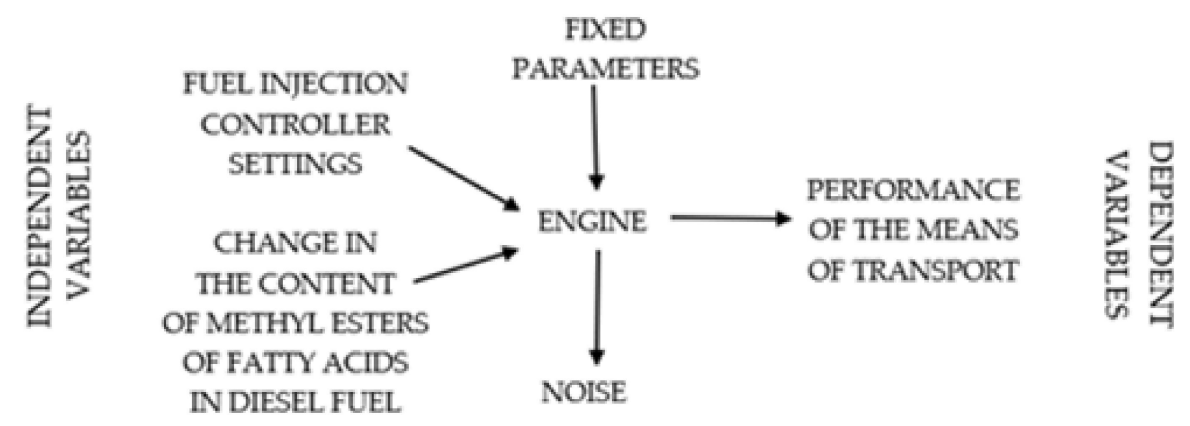

Figure 4. Scheme of the experiment program.

Tests of the engines powered with mixtures of variable contents of fatty acid methyl esters and diesel oil, and with a modified fuel injection controller were conducted by means of a load bearing chassis dynamometer equipped with an eddy current brake. Use of a chassis dynamometer made it possible to obtain data necessary for determination of performance characteristics for transport means internal combustion engines such as: power and torque. The device measured the torque transmitted to the crankshaft and calculated the engine power basing on the value of torque and rotational speed of 
the crankshaft. The measurement was affected by air moisture, atmospheric pressure changes and the air temperature whose values are normalized. The measurement results were converted into values corrected according to the valid norm $\left(25^{\circ} \mathrm{C}\right.$ and $\left.1000 \mathrm{hPa}\right)$. The goal of the tests was:

- to check the parameters reached by internal combustion engines mounted in vehicles (moment torque, power and loading characteristics),

- to measure the engine parameters after intervention and its adjustments (fuel injection controller adjustment), and

- to check sound emission, emission of toxic exhaust gas components and PM by means of additional analyzers.

The rule for the measurement of the engine parameters with the use of a chassis dynamometer involved the simulation of road conditions and exposure of the vehicles to respective loading. The chassis dynamometer consists of a suspension system with a braking system, engine cooling system and a control-measurement system (Figure 5). Technical data of the chassis dynamometer are presented in Table 4.

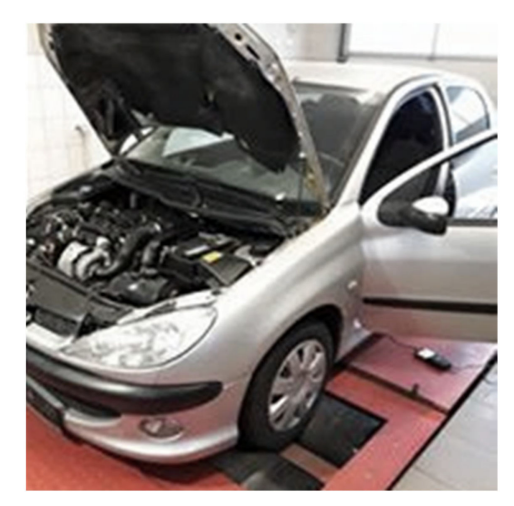

Figure 5. Load bearing chassis dynamometer used in the tests.

Table 4. Technical data of the chassis dynamometer.

\begin{tabular}{cc}
\hline Chassis Dynamometer Type & Load Bearing \\
\hline Maximum speed & $288 \mathrm{~km} / \mathrm{h}$ \\
Maximum torque on the wheels & $1300 \mathrm{Nm}$ per one axle \\
Maximum power & $900 \mathrm{HP}$ per one axle \\
Maximum torque on the engine & $1000 \mathrm{Nm}$ per one axle \\
mass & $3000 \mathrm{~kg}$ \\
length/width/height & $3800 / 4500 / 500 \mathrm{~mm}$ \\
maximum/minimum track width & $2100 / 700 \mathrm{~mm}$ \\
maximum/minimum track width & $3350 / 2350 \mathrm{~mm}$ \\
\hline
\end{tabular}

Measurements of the performance parameters were performed according to the following schedule:

- the vehicles were placed and secured in the chassis dynamometer by means of belts so that they would not move, and the wheels were blocked by a special blockade,

- prior to the tests the internal combustion engines were fully heated (the temperature of coolant was app. $\left.85^{\circ} \mathrm{C}\right)$; its value was checked before each measurement,

- necessary sensors and probes (temperature sensors, pressure sensors, probes for exhaust emission components and $\mathrm{PM}$ ) were connected to each vehicle,

- a test measurement was performed to make it possible for the chassis dynamometer system to automatically determine the position of the gear box and main gear (position of the main transmission gear) for which the main measurement is to be performed, 
- changes were introduced to the vehicle engine computer software (fuel injection controller settings) during the measurements,

- airflow system was turned on to simulate a real air movement for a moving vehicle (dynamometer fan), and

- each tested vehicle was accelerated (up to the maximum engine speed) to reach the maximum level of revolutions, then the drive was declutched, leaving the vehicle in the gear. The vehicles were decelerating due to the inertial force of a speeding roller when the measurement of the system losses was performed.

The measurement of the concentration of exhaust emission toxic components was carried out by means of an exhaust emission analyzer MGT-5. Analysis of exhaust gases made it possible to define the quantity of exhaust emission components which are discharged to the atmosphere in the form of exhaust gases. The described device is used for measuring the amount of exhaust components and is designed to determine the values of: $\mathrm{O}_{2}, \mathrm{CO}, \mathrm{CO}_{2}$ and $\mathrm{NO}_{2}$. The analyzer was controlled by a PC. The measurement of $\mathrm{CO}, \mathrm{CO}_{2}$, and $\mathrm{NO}_{2}$ contained in the exhaust gases was carried out by $\mathrm{x}$-raying the exhaust gases with an infrared beam, whereas the measurement of oxygen was conducted using the electrochemical method.

The measurement of PM contained in exhaust emission was performed according to the optical method with the use of an MPM-4 analyzer. The optical method involves comparing the infrared absorption of an indifferent model gas and the analyzed compound. PM produced by fuel combustion in self ignition engines are particles of carbon and smaller particles are absorbed by it, that is, soot. The value of PM emitted during the fuel combustion was calculated based on statistical values. The distribution of the PM dimensions, was determined using an electronic meter of particles.

The noise generated by the engines was measured by a sonometer equipped with a spectral analyzer meeting the requirements of IEC 61672-1:2002 and IEC 60651 norms. The assessment of the sound level depended on its duration time and the noise level. These two values were determined for the maximum loading of the internal combustion engine. Because of the emitted sound variability in time, acoustic pressure was sampled in selected time intervals which resulted in the sound level being denoted as $L_{e q}$. The determination of acoustic pressure for individual bands enabled the reconstruction of the radiation spectrum during the test of sound generated by the internal combustion engine. Acoustic parameter values of the tested engines were determined by means of the orientation method for determination of the engine noise acoustic power level. This method involved calculating the corrected level of acoustic power, the acoustic power level in frequency bands based on acoustic pressure in frequency bands, and the level of sound measured with the use of a correction filter. The measuring surface formed a closed area around the engines to bounce off the sound and its distance from the tested internal combustion engine was $1 \mathrm{~m}$, whereas the height was equal to the height the engines were mounted at.

\section{Results}

Based on the literature analysis and the authors' own tests with the use of real objects, a resultant model was developed which was supposed to represent procedures to be followed in successive steps (mixture changes and fuel injection controller settings). The paper presents the selected performance parameters of internal combustion engines that have been tested. The model built for assessment of internal combustion engine operation in modified operation conditions was verified by means of fuzzy logic elements. The results obtained from the tests of internal combustion engines were statistically analyzed. The test results also provided the basis for the development of a computer simulation algorithm.

\subsection{Statistical Analysis}

Firstly, the distributions of the internal combustion engine performance parameters were tested by application of consistency test of $\lambda$ Kołmogorow. (Figure 6)The test was conducted for eight values of performance parameters of the tested transport means for a configuration mixture-fuel injection 
controller setting. The study includes a sample check of $\lambda$ Kołmogorow consistency of power for the first setting of the fuel injection controller. An interval for which the population of measurements occurring in this interval was assigned for the analyzed parameter. To verify the hypothesis that the empirical distribution is equal to the theoretical distribution function (hypothetical), 150 measurements were tested. The results were used for the determination of the value of $\lambda$ Kołmogorow statistics of the power test for setting I of the fuel injection controller. A value of $p=0.51>0.05$ corresponds to the value of this statistics which was 0.82702 . The obtained result proves that there are no grounds on which to reject the hypothesis of distribution normality.

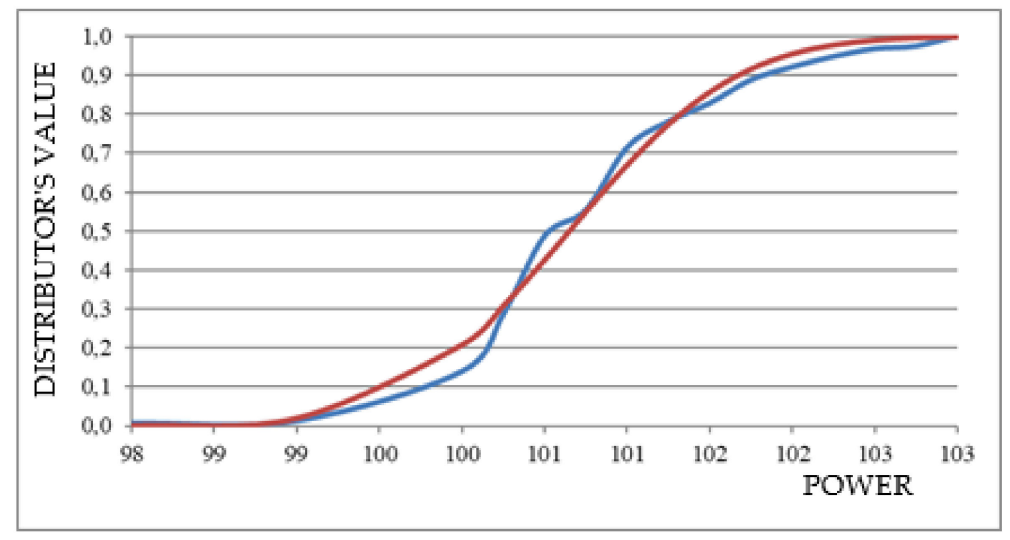

Figure 6. Graphic presentation of empirical and theoretical distribution functions in $\lambda$ Kołmogorow test.

The next analysis consisted in comparing mean values for three mixtures of diesel oil and fatty acid methyl esters. Four tests were carried out for each setting of the fuel injection controller (I, II, III, IV). Each time, eight performance parameters of transport means internal combustion engines were tested. Mean values were assumed to be equal for all the mixtures as a zero hypothesis. The obtained significance levels are presented in Table 5.

Table 5. Verification of the hypothesis for the tested parameters.

\begin{tabular}{ccccc}
\hline Parameter & \multicolumn{4}{c}{ Number of Setting } \\
\cline { 2 - 5 } & I & II & III & IV \\
\hline power [kW] & 0.0001 & 0.0001 & 0.0001 & 0.0001 \\
Torque [Nm] & 0.0001 & 0.0001 & 0.0001 & 0.0001 \\
Emission of sound generated by the engine [dB] & 0.0001 & 0.0001 & 0.0001 & 0.0001 \\
PM contained in exhaust gases [ppm] & 0.0001 & 0.0001 & 0.0001 & 0.0001 \\
CO [\% obj.] & 0.0001 & 0.0009 & 0.0496 & 0.0029 \\
$\mathrm{CO}_{2}[\%$ obj.] & 0.5014 & 0.0009 & 0.1945 & 0.0001 \\
$\mathrm{O}_{2}[\%$ obj.] & 0.0001 & 0.0001 & 0.0001 & 0.0001 \\
$\mathrm{NO}_{2}[\mathrm{ppm}]$ & 0.0001 & 0.0001 & 0.0043 & 0.0043 \\
\hline
\end{tabular}

The table includes the results of significance level tests where $p=0.0001$ means that the real significance level is lower. Only in two cases (for carbon dioxide for fuel injection controller adjustment: I and II) were there no grounds to reject the hypothesis of the mean values equality.

The analysis was used for verification of the hypothesis of significance of differences between the mean values to find out whether the obtained coefficients vary significantly from zero. Based on the results significantly different from zero it is possible to determine a regression function and to use it as a tool for the prognosis of a value of one characteristic based on the value of the second characteristic.

According to the $\lambda$ Kołmogorow consistency test, a one-dimensional distribution of the studied characteristics can be considered normal. The population which was analyzed yielded a 150 -element test $\mathrm{n}$, which provided the studied characteristics $\mathrm{x}$ and $\mathrm{y}$ with specific measurement conditions. 
$\mathrm{X}$ was used to mark the applied mixture and $\mathrm{y}$ to mark the results being of tests of the performance parameter values of transport means internal combustion engines for respective settings of the engine fuel injection controller. Thus, in the regression analysis, the fuel injection controller settings are independent variables, whereas the accepted performance parameters are dependent variables. Interpretation of the regression function in the case of self-ignition powered with mixtures of diesel oil and fatty acid methyl esters applies to usefulness of the statistical model variables to predict the level of dependent variables.

Exemplary regression equations have been presented for the sound emission test and fuel injection controller setting I (Figure 7). A regression line which can be considered linear was obtained by marking the empirical points on the diagram.

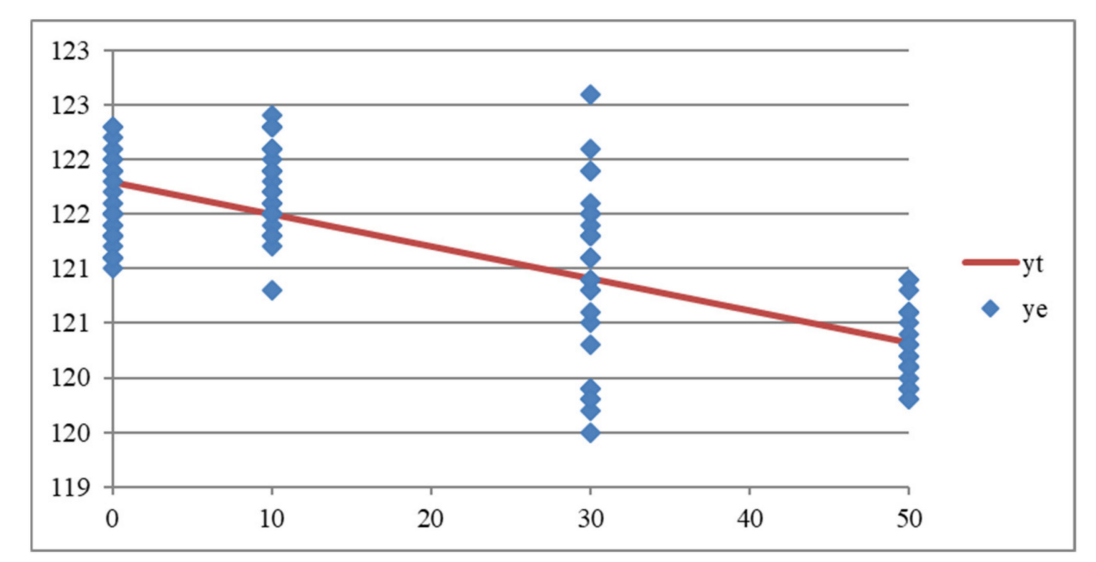

Figure 7. linear regression diagram for the studied sound emission parameter for I fuel injection controller adjustment.

In the above diagram there are empirical points denoted as $\mathrm{y}_{\mathrm{e}}$, along with regression line $\mathrm{y}_{\mathrm{t}}$ determined for theoretical parameters.

The values of estimators $a$ and $b$ were determined by the method of the smallest squares. Differences between the measurement values and their mean value as well as the values of defined functions were also calculated. Based on this, a regression line was defined to be:

$$
y=0.0292 x+121.788
$$

The correlation coefficient for the above regression equation was $r=-0.732$. The tested hypothesis $\mathrm{H}_{0}$ : and $=0$ yielded $\mathrm{p}<0.0001$, which means that the tested relationship is statistically significant.

\subsection{Resultant Model}

A model for the operation assessment of transport means powered with mixtures of diesel oil and fatty acid methyl esters was built from the point of view of the fuel injection controller settings. Each performance parameter of the test internal combustion engines (characteristic) was a one-dimensional random variable which reflected the assessment of transport means functioning [43].

The random variable of a given object is defined as follows:

$$
Z_{x}=\sum_{i=1}^{p} \alpha_{i} X_{i}
$$

where

$$
: \alpha_{i} \geq 0, \sum_{i=1}^{p} \alpha_{i}=1 \text {, }
$$


where $\alpha_{i}, i=1,2, \ldots, p$ - denote the values of weights for particular performance parameters and $Z_{X^{-}}$ is a random variable being a limited mixture of variable $X_{i}, i=1,2, \ldots, p$.

For the considered $Z_{X}$ the following inequality is as follows:

$$
Z_{x} \leq \sum_{i=1}^{p} \alpha_{i} q_{i}
$$

The above inequality indicates that random variable $Z_{X}$ defined by means of equality (3) is limited, that is, the values of parameters accepted for the assessment, will not exceed a pre-defined threshold, that is, the right side of inequality (3).

Based on this, vectors were determined which were resultant in an eight -dimensional space of state representing the overall assessment of the study objects. Since the aim of the analysis was to provide a comparative assessment of transport means powered with different mixtures and with different fuel injection controller settings, the performance parameters of diesel oil powered transport means internal combustion engines and factory settings were accepted to be the point of reference. Whereas to provide clarity and adequacy of the description, the obtained results were normalized into $<0 \div 10>$ intervals during the construction of the vectors using a dependence:

$$
10 \times \frac{\left(X_{i}-X_{\min }\right)}{\left(X_{\max }-X_{\min }\right)}
$$

Twelve measurement configurations including three diesel oil mixtures with fatty acid methyl esters and fuel injection controller settings as well as four fuel injection controller settings were normalized. Standardized tests results are presented in Table 6.

\begin{tabular}{|c|c|c|c|c|c|c|}
\hline \multirow{2}{*}{ Mixture } & \multirow{2}{*}{ Parameter } & \multirow{2}{*}{ Vector Component Denotation } & \multicolumn{4}{|c|}{ Number of Setting } \\
\hline & & & $\mathbf{I}$ & II & III & IV \\
\hline \multirow{8}{*}{$\mathrm{ON}$} & power & $\mathrm{X}_{1}$ & 4.53 & 1.06 & 6.23 & 7.66 \\
\hline & torque & $x_{2}$ & 5.54 & 5.97 & 5.05 & 6.99 \\
\hline & noise & $x_{3}$ & 4.38 & 3.59 & 5.73 & 4.60 \\
\hline & $\mathrm{PM}$ & $\mathrm{X}_{4}$ & 7.00 & 5.62 & 4.13 & 5.36 \\
\hline & $\mathrm{CO}$ & $X_{5}$ & 2.07 & 1.48 & 0.70 & 2.48 \\
\hline & $\mathrm{CO}_{2}$ & $x_{6}$ & 4.47 & 7.40 & 5.73 & 8.15 \\
\hline & $\mathrm{O}_{2}$ & $x_{7}$ & 4.81 & 1.58 & 2.09 & 3.31 \\
\hline & $\mathrm{NO}_{2}$ & $\mathrm{X}_{8}$ & 5.68 & 6.57 & 7.28 & 6.78 \\
\hline \multirow{8}{*}{ B30 } & power & $\mathrm{X}_{\mathrm{B} 1}$ & 8.56 & 6.68 & 4.51 & 5.83 \\
\hline & torque & $\mathrm{X}_{\mathrm{B} 2}$ & 5.70 & 4.21 & 4.93 & 5.08 \\
\hline & noise & $\mathrm{X}_{\mathrm{B} 3}$ & 4.77 & 5.44 & 5.67 & 6.00 \\
\hline & $\mathrm{PM}$ & $\mathrm{X}_{\mathrm{B} 4}$ & 4.14 & 4.14 & 4.76 & 4.66 \\
\hline & $\mathrm{CO}$ & $\mathrm{X}_{\mathrm{B} 5}$ & 1.18 & 2.13 & 2.33 & 1.52 \\
\hline & $\mathrm{CO}_{2}$ & $\mathrm{X}_{\mathrm{B} 6}$ & 6.52 & 8.97 & 1.66 & 7.83 \\
\hline & $\mathrm{O}_{2}$ & $\mathrm{X}_{\mathrm{B} 7}$ & 2.74 & 3.75 & 3.43 & 2.95 \\
\hline & $\mathrm{NO}_{2}$ & $\mathrm{X}_{\mathrm{B} 8}$ & 4.05 & 5.89 & 5.74 & 5.97 \\
\hline \multirow{8}{*}{ B50 } & power & $\mathrm{X}_{\mathrm{C} 1}$ & 5.24 & 3.41 & 5.05 & 4.44 \\
\hline & torque & $x_{C 2}$ & 4.83 & 5.70 & 6.23 & 4.86 \\
\hline & noise & $x_{\mathrm{C} 3}$ & 3.97 & 5.51 & 3.03 & 5.28 \\
\hline & $\mathrm{PM}$ & $X_{C 4}$ & 6.56 & 5.18 & 5.36 & 5.00 \\
\hline & $\mathrm{CO}$ & $X_{C 5}$ & 1.80 & 1.49 & 2.21 & 1.66 \\
\hline & $\mathrm{CO}_{2}$ & $\mathrm{X}_{\mathrm{C} 6}$ & 8.34 & 8.27 & 9.19 & 3.67 \\
\hline & $\mathrm{O}_{2}$ & $X_{C 7}$ & 4.94 & 2.93 & 3.17 & 2.36 \\
\hline & $\mathrm{NO}_{2}$ & $\mathrm{X}_{\mathrm{C} 8}$ & 7.58 & 5.82 & 9.22 & 6.95 \\
\hline
\end{tabular}

Table 6. Verification of the hypothesis for the analyzed parameters. 
The results obtained in this way enabled graphic interpretation of the vectors and their components. In this study, two vectors are presented (Figure 8) for configurations: mixture B30 and setting II and mixture B50 and setting III, which are referred to mixture ON and setting I.

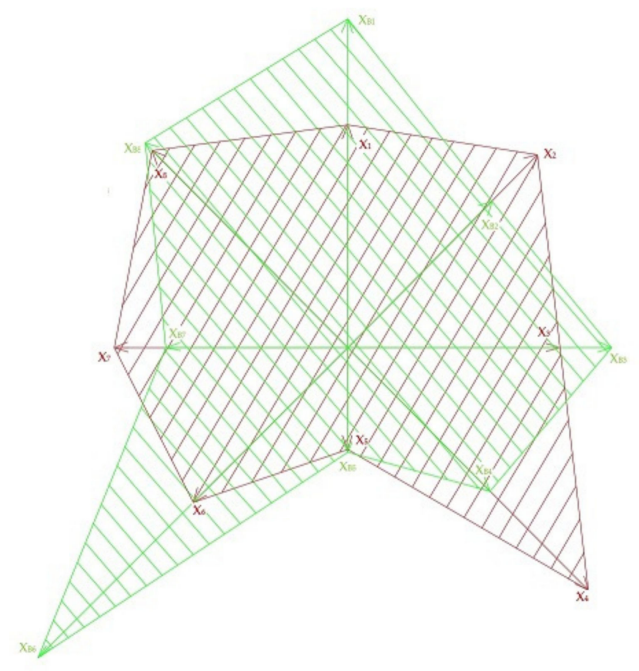

(a)

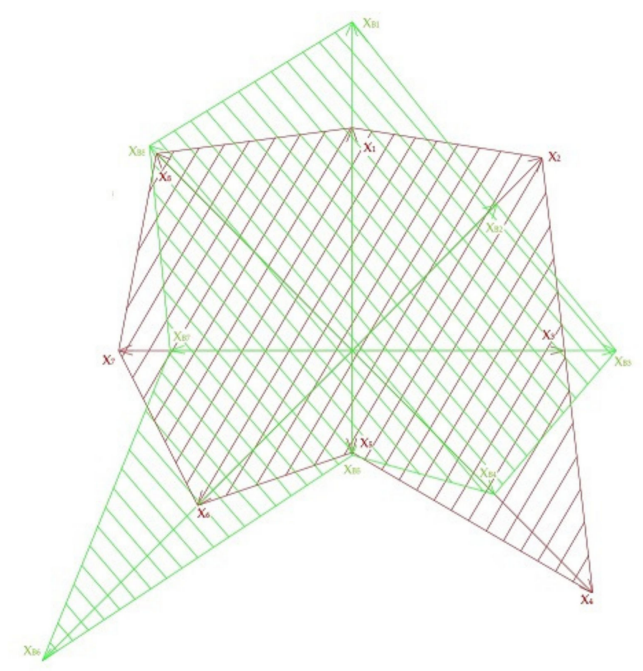

(b)

Figure 8. Graphic interpretation of vector components for: (a) mixture B30 and setting II; (b) mixture B50 and setting III.

Weights $(\alpha)$ were determined by means of the AHP method (analytical hierarchy process) for the needs of each tested performance parameter. (Table 7) The values of weights for the performance parameters are presented in Figure 7. The determined weights were used to define the standardized results of random variable $Z_{x}$, which has the following form:

$$
Z_{X}=\alpha_{1} X_{1}+\alpha_{2} X_{2}+\alpha_{3} X_{3}+\alpha_{4} X_{4}+\alpha_{5} X_{5}+\alpha_{6} X_{7}+\alpha_{7} X_{7}+\alpha_{8} X_{8}
$$

Table 7. Values of the performance parameter weights.

\begin{tabular}{ccc}
\hline Weight Denotation & Explanation & Weight \\
\hline$\alpha_{1}$ & power [kW] & 0.2616 \\
$\alpha_{2}$ & torque [Nm] & 0.45547 \\
$\alpha_{3}$ & noise [dB] & 0.01239 \\
$\alpha_{4}$ & PM [ppm] & 0.2616 \\
$\alpha_{5}$ & $\mathrm{CO}[\%$ obj.] & 0.00054 \\
$\alpha_{6}$ & $\mathrm{CO}_{2}[\%$ obj.] & 0.00245 \\
$\alpha_{7}$ & $\mathrm{O}_{2}[\%$ obj.] & 0.00056 \\
$\alpha_{8}$ & $\mathrm{NO}_{2}[\mathrm{ppm}]$ & 0.00539 \\
\hline
\end{tabular}

Random variables $Z_{x}$ were determined for twelve configurations of mixture-fuel injection setting. Each variable represents a vector which consists of eight performance parameters each assigned with significance degree. The value of the variables and their mutual dependencies are presented in a diagram (Figure 9). The diagram shows random variables $Z_{x}$, which were ordered according to the measurements. 


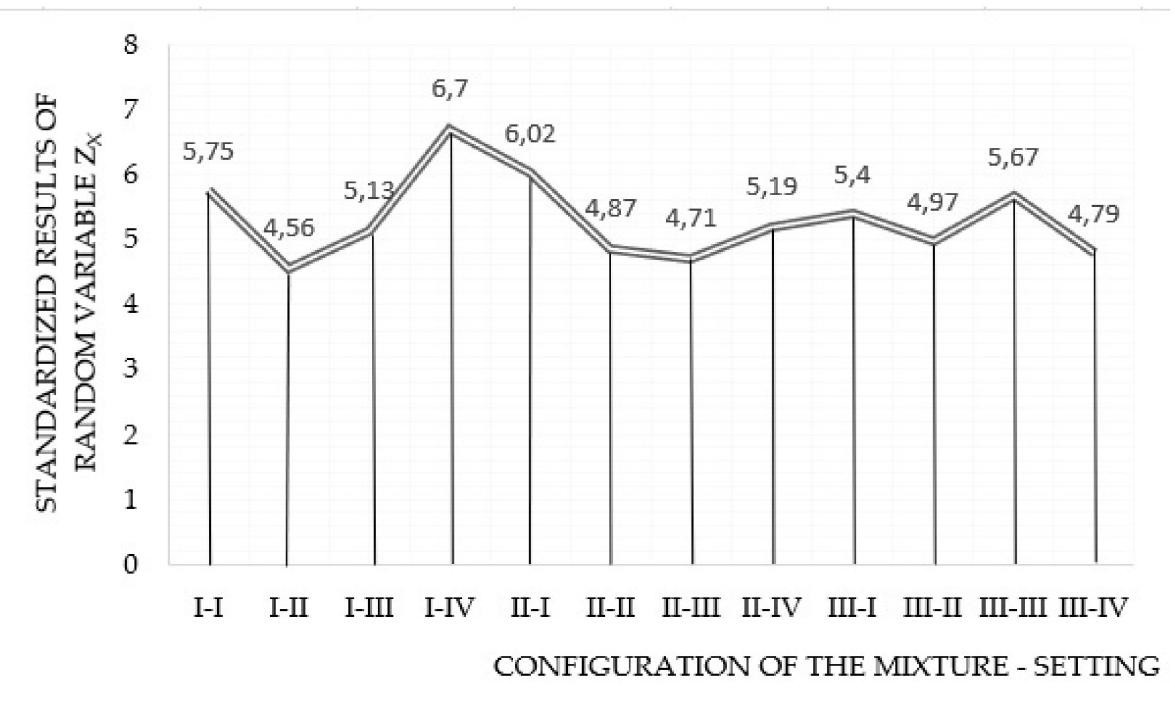

Figure 9. Graphic interpretation of random variable value Zx.

The study was verified by means of the mean fuzzy diagram method. The analysis was performed with the use of an original program [46], which was adjusted to the needs of this study. Equal weights were established for all the tested parameters and assessment of each configuration (mixture-setting) was made. Three performance parameters sensitive to the mixture change and fuel injection controller setting can be distinguished based on the obtained data. Parameters most sensitive to introduced changes were exhaust emission components $\left(\mathrm{O}_{2}, \mathrm{CO}, \mathrm{CO}_{2}\right.$ and $\left.\mathrm{NO}_{2}\right)$.

\subsection{Simulation Tests}

A computer simulation algorithm was developed to enable the prognosis of the tested objects functioning in dependence on the type of fuel mixtures and setting of the fuel injection controller. The application of this algorithm allowed for the assessment of the impact of value change of the parameters identified for the description of the analyzed research object in terms of the changes being introduced.

The algorithm consists of two modules: a module of statistical analysis and a module of simulation of the impact of performance parameter value change of an internal combustion engine. Input data for the statistical analysis module is a file which includes the values of parameters which occur in the model description. The simulation module generated the value change of each parameter based on the input data and determined the values of matrixes describing its state.

Simulation tests were performed according to the following schedule:

1. give the number of observations to be generated and the system parameters to be analyzed,

2. define parameters of random variable distribution basing on verification of the hypothesis of empirical distribution with theoretical distributions,

3. generate values of the $i$-th parameter $(i=1,2, \ldots, p)$, from distributions: discrete or continuous,

4. determine boundary values for each parameter,

5. normalize the values of generated random variables according to the accepted assumptions,

6. determine mean values of the obtained assessments,

7. calculate the values of the parameters basing on the accepted matrix,

8. determine the values of weights for each parameter,

9. define models od value changes of each parameter,

10. generate the results of performed tests in the form of reports,

11. archive the simulation results, and

12. print the simulation results. 
The computer simulation algorithm was used for state prognosis of the tested transport means powered with a mixture of diesel oil and fatty acid methyl esters for different settings of the fuel injection controller. It was also used for assessment of the developed model sensitivity and the response to its input parameter value change.

\section{Discussion}

An analysis of the state of knowledge in the studied area shows that the use of biofuels to power self-ignition engines causes reduction of exhaust emission components discharged to the natural environment [28,40-50]. The tests of real transport objects for the engine factory settings confirm power and torque decrease and reduction in the amount of exhaust components $[9,43,44,49-57]$. The literature provides no information on the research into internal combustion engines powered with diesel oil and fatty acid methyl esters in different proportions for different fuel injection controller settings, nor an adequate model for an assessment method of the impact of use of biocomponent additive in diesel oil.

\section{Conclusions}

Based on the tests performed, it can be said that the addition of fatty acid methyl esters to diesel oil does have an impact on the amount of exhaust emission components. A statistical analysis has revealed that the parameters tested for different configurations of mixture-fuel injection controller setting are statistically significant. In only two cases (for carbon dioxide and for fuel injection controller setting: I and II) were there no grounds to reject the hypothesis of the mean value equality. A $30 \%$ content of fatty acid methyl esters application as an additive to diesel oil (for the engine factory settings) is a boundary value of its usability due to the criterion of power and torque. However, it needs to be noted that the changes fuel injection controller settings caused rise power and torque of engines powered with mixtures of fatty acid methyl esters and diesel oil. Increasing the fuel dose and supplying air load to the engines improved performance similarly to that of diesel oil. An analysis of the values of the studied internal combustion engine performance parameters based on a random variable defined for these test objects has confirmed that the highest results in relation to factory settings and diesel oil were obtained for the configuration ON- setting IV, B30- setting I, and B50- setting III. According to a 10-grade scale, the assessment of the impact of fuel injection controller setting on the values of performance parameters of transport powered with mixtures of fatty acid methyl esters and diesel oil was found to be the highest for setting I of mixture II and was equal to eight, and the difference between the highest and the lowest grades for particular mixtures was about $16 \%$.

Tests and analyses of the performance parameters of internal combustion engines powered with diesel oil with additives of methyl esters have revealed that the most important parameters having an influence on the analyzed internal combustion engines are those which directly affect the natural environment.

These results provide the basis for further analyses to be performed in order to develop a mathematical model for the determination of adequate settings of the fuel injection controller depending on the composition of the applied fuel mixture, which will be expressed in the form of a continuous function.

Author Contributions: Conceptualization: Ł.M., M.M.; formal analysis: Ł.M., M.M.; investigation: M.M.; methodology: Ł.M., M.M.; resources: M.M.; visualization: M.M.; writing—original draft: M.M.; writing一review and editing: M.M.

Funding: The research did not receive external financing.

Conflicts of Interest: The authors declare no conflict of interest.

\section{References}

1. Agarwal, A. Biofuels (alcohols and biodiesel) applications as fuels for internal combustion engines. Prog. Energy Combust. Sci. 2007, 33, 233-271. [CrossRef] 
2. Salvi, B.; Subramanian, K.; Panwar, N. Alternative fuels for transportation vehicles: A technical review. Renew. Sustain. Energy Rev. 2013, 25, 404-419. [CrossRef]

3. Brandt, A.; Millard-Ball, A.; Ganser, M.; Gorelick, S. Peak oil demand: The role of fuel efficiency and alternative duels in a global oil production decline. Environ. Sci. Technol. 2013, 14, 831-841. [CrossRef]

4. Mahmudul, H.; Hagos, F.; Mamat, R.; Abdul, A.; Ishak, W.; Alenezi, R. Production, characterization and performance of biodiesel as an alternative fuel in diesel engines-A review. Renew. Sustain. Energy Rev. 2017, 72, 497-509. [CrossRef]

5. York, R. Do alternative energy sources displace fossil fuels? Nat. Clim. Chang. 2012, 2, 441-453. [CrossRef]

6. Singh, J. Commercialization potential of microalgae for biofuels production. Renew. Sustain. Energy Rev. 2010, 14, 2596-2610. [CrossRef]

7. Singh, A.; Nigan, P.; Murphy, J. Renewable fuels from algae: An answer to debatable land based fuels. Bioresour. Technol. 2011, 102, 10-16. [CrossRef]

8. Naik, S.; Goud, V.; Rout, P.; Dalai, A. Production of first and second generation biofuels: A comprehensive review. Renew. Sustain. Energy Rev. 2010, 14, 578-597. [CrossRef]

9. Banapurmath, N.; Tawari, P.; Hosmath, R. Performance and emission characteristics of a DI compression ignition engine operated on Honge, Jatropha and sesame oil methyl esters. Renew. Energy 2008, 33, 1982-1988. [CrossRef]

10. Ghobadian, B.; Rahimi, H.; Nikbakht, A.; Najafi, G.; Yusaf, T. Diesel engine performance and exhaust emission analysis using waste cooking biodiesel fuels with an artificial neural network. Renew. Energy 2009, 34, 976-982. [CrossRef]

11. Gang, W.; Guohe, J.; Zhiyuan, Y.; Zhijian, H. Emission characteristics for waste cooking oil biodiesel blend in a marine diesel propulsion engine. Pol. J. Environ. Stud. 2019, 28, 2911-2921.

12. Qian, Y.; Sun, S.; Ju, D.; Shan, X.; Lu, X. Review of the state-of-the-art of biogas combustion mechanisms and applications in internal combustion engines. Renew. Sustain. Energy Rev. 2017, 69, 50-58. [CrossRef]

13. Alemayehu, G.; Abile, T. Production of biodiesel from waste cooking oil and factors affecting its formation: A review. Int. J. Renew. Sustain. Energy 2014, 3, 92-98.

14. Zivkovic, S.; Veljković, M. Environmental impacts of the production and use of biodiesel. Environ. Sci. Pollut. Res. 2018, 25, 191-199. [CrossRef] [PubMed]

15. Nurun, N.; Mostafizur, R.; Muhammad, A.; Farhad, H.; Brooksc, P.; Rowlandsd, W.; Tullochd, J.; Ristovskia, Z.; Browna, R. Fuel characterisation, engine performance, combustion and exhaust emissions with a new renewable Licella biofuel. Energy Convers. Manag. 2015, 96, 588-598.

16. Xua, Y.; Keresztesb, I.; Condo, A.; Phillipsc, J.; Pepiota, P.; Avedisian, T. Droplet combustion characteristics of algae-derived renewable diesel, conventional 2 diesel, and their mixtures. Fuel 2016, 167, 95-305. [CrossRef]

17. Saifullah, A.; Karim, A.; Ahmad-Yazid, A. Microalgae: An Alternative Source of Renewable Energy. Am. J. Eng. Res. 2014, 3, 330-338.

18. Zaharina, M.; Abdullaha, N.; Najafib, G.; Sharudina, H.; Yusafc, T. Effects of physicochemical properties of biodiesel fuel blends with alcohol on diesel engine performance and exhaust emissions: A review. Renew. Sustain. Energy Rev. 2017, 79, 475-493. [CrossRef]

19. Wakila, M.; Kalama, M.; Masjukia, H.; Atabanib, A.; Rizwanul, I. Influence of biodiesel blending on physicochemical properties and importance of mathematical model for predicting the properties of biodiesel blend. Energy Convers. Manag. 2015, 94, 51-67. [CrossRef]

20. Golimowski, W.; Krzaczek, P.; Marcinkowski, D.; Gracz, W.; Wałowski, G. Impact of biogas and waste fats methyl esters on NO, NO2, CO, and PM emission by dual fuel diesel engine. Sustainability 2019, 11, 1799. [CrossRef]

21. Golimowski, W.; Marcinkowski, D.; Gracz, W.; Konieczny, R.; Poczta, O.; Czechlowski, M.; Krzaczek, P.; Piekarski, W. Determination of methyl palmitate content in fatty acid methyl esters by near infrared spectroscopy. Przem. Chem. 2017, 12, 2522-2526.

22. Marcinkowski, D.; Rukowicz, B.; Golimowski, W.; Czechlowski, M.; Krzaczek, P.; Ppiekarski, W. Effect of selected depressants on cold filter plugging point for methyl esters obtained from transesterification of waste vegetable and animal fats. Przem. Chem. 2017, 9, 1927-1930.

23. Wasilewski, J.; Krzaczek, P. Emission of toxic compounds from combustion of biodiesel. A raport from studies. Przem. Chem. 2014, 3, 343-346. 
24. Ganapathya, T.; Gakkharb, R.; Murugesanb, K. Influence of injection timing on performance, combustion and emission characteristics of Jatropha biodiesel engine. Appl. Energy 2011, 88, 4376-4386. [CrossRef]

25. Zhenga, M.; Mulengaa, M.; Readerb, G.; Wanga, M.; Tinga, D.; Tjongc, J. Biodiesel engine performance and emissions in low temperature combustion. Fuel 2008, 8, 714-722. [CrossRef]

26. Canakcia, M.; Erdilb, A.; Arcaklioğluc, E. Performance and exhaust emissions of a biodiesel engine. Appl. Energy 2006, 83, 594-606. [CrossRef]

27. Mofijur, M.; Rasul, M.; Hyde, J.; Bhuyia, M. Role of biofuels on IC engines emission reduction. Energy Procedia 2015, 75, 886-892. [CrossRef]

28. Fontaras, G.; Karavalakis, G.; Kousoulidou, M.; Tzamkiozis, T.; Ntziachristos, L.; Bakeas, E.; Stournas, S.; Samaras, Z. Effects of biodiesel on passenger car fuel consumption, regulated and non-regulated pollutant emissions over legislated and real-world driving cycles. Fuel 2009, 88, 1608-1617. [CrossRef]

29. Demirbas, A. Importance of biodiesel as transportation fuel. Energy Policy 2007, 35, 4661-4670. [CrossRef]

30. Halleux, H.; Lassaux, S.; Renzoni, R.; Germain, A. Comparative life cycle assessment of two biofuels ethanol from sugar beet and rapeseed methyl ester. Int. J. Life Cycle Assess. 2008, 13, 184-190. [CrossRef]

31. Labeckas, G.; Slavinskas, S. The effect of rapeseed oil methyl ester on direct injection Diesel engine performance and exhaust emissions. Energy Convers. Manag. 2006, 47, 1954-1967. [CrossRef]

32. Rajagopal, D.; Hochman, G.; Zilberman, D. Indirect fuel use change (IFUC) and the lifecycle environmental impact of biofuel policies. Energy Policy 2011, 39, 228-233. [CrossRef]

33. Mittelbach, M.; Remschmidt, C. Biodiesel. The comprehensive Handbook; Boersedruck Ges.m.b.H: Vienna, Austria, 2004.

34. Heywood, J.B. Internal Combustion Engine Fundamentals; Mc Graw-Hill Education: New York, NY, USA, 1989.

35. Szlachta, Z.; Cisek, J. The Autoignition Delay of Vegetable Fuels at Varied Air Temperatures inside Combustion Chamber of Diesel Engine; AGROTECH: Nitra, Slovakia, 2001.

36. Markiewicz-Patalon, M.; Muślewski, Ł.; Kaszkowiak, J. Noise emission research of diesel engine powered with mixture of diesel oil and methyl esters. In Proceedings of the Scientific Automotive Conference KONMOT, Cracow, Poland, 13-14 September 2018; pp. 272-274.

37. Markiewicz-Patalon, M.; Muślewski, Ł.; Kaszkowiak, J.; Sójka, M. Analysis of efficiency of the vehicle transport facilities powered with diesel oil with additive of biocomponent. In Proceedings of the Scientific Automotive Conference KONMOT, Krakow, Poland, 13-14 September 2016; pp. 279-299.

38. Landowski, B. Numerical simulation of the process of a technical object state changes. J. KONBiN 2018, 45, 247-266. [CrossRef]

39. Kostek, R.; Landowski, B.; Muślewski, Ł. Simulation of rolling bearing vibration in diagnostics. J. Vibroeng. $2015,17,4268-4278$.

40. Agarwal, A.K.; Srivastava, D.K.; Dhar, A.; Maurya, R.K.; Shukla, P.C.H.; Singh, A.P. Effect of fuel injection timing and pressure on combustion, emissions and performance characteristics of a single cylinder diesel engine. Fuel 2013, 111, 374-383. [CrossRef]

41. Arapaki, N.; Bekeas, E.; Karavalakis, G.; Tzirakis, E.; Stournas, S.; Zannikos, F. Regulated and unregulated emission characteristics of diesel vehicle operating with diesel biodiesel blend. SAE Tech. Pap. 2007, 1, 1-9.

42. Armas, O.; Yehliu, K.; Boehman, A. Effect of alternative fuels on exhaust emission during diesel engine operation with matched combustion phasing. Fuel 2010, 89, 438-456. [CrossRef]

43. Azoumaha, Y.; Blinac, J.; Dahob, T. Exergy efficiency applied for the performance optimization of a direct injection compression ignition engine using biofuels. Renew. Energy 2009, 34, 1494-1500. [CrossRef]

44. Tompkins, B.; Song, H.; Bittle, J.; Jacobs, T. Efficiency considerations for the use of blended biofuel in diesel engines. Appl. Energy 2012, 98, 209-218. [CrossRef]

45. Bala, B.K. Studies on biodiesels from transformation of vegetable oils for diesel engines. Energy Educ. Sci. Technol. 2005, 15, 1-43.

46. Choi, S.; Oh, Y. The emission effects caused by the use of biodiesel fuel. Int. J. Mod. Phys. B 2006, 20, 4481-4486. [CrossRef]

47. Knothe, G.; Sharp, C.; Ryan, T. Exhaust emission of biodiesel, petrodiesel, neat methyl esters and alkanes in a new technology engine. Energy Fuels 2006, 20, 403-408. [CrossRef]

48. Lapuerta, M.; Armas, O.; Rodriguez-Fernandez, L. Effect of biodiesel fuels on diesel engine emission. Prog. Energy Combust. Sci. 2008, 34, 198-223. [CrossRef] 
49. Leung, D.; Luo, Y.; Chan, T. Optimization of exhaust emission of a diesel engine fueled with biodiesel. Energy Fuels 2006, 20, 105-111. [CrossRef]

50. Agarwal, A.D.; Sinhab, S.; Agarwal, A.K. Experimental investigation of control of NOx emission in biodiesel-fueled compression ignition engine. Renew. Energy 2006, 31, 2356-2369. [CrossRef]

51. Correa, S.; Arbilla, G. Carbonyl emission in diesel and biodiesel exhaust. Atmos. Environ. 2008, 44, 769-775. [CrossRef]

52. Hansen, A.; Gratton, M.; Yuan, W. Diesel engine performance and NOx emission from oxygenated biofuels and blends with diesel fuel. Trans. ASABE 2006, 49, 589-595. [CrossRef]

53. Muślewski, Ł. Evaluation Method of transportation systems operation quality. Pol. J. Environ. Stud. 2009, 18, 145-151.

54. Pająk, M.; Muślewski, Ł.; Landowski, B.; Grządziela, A. Fuzzy identification of the reliability state of the mine detecting ship propulsion system. Pol. Marit. Res. 2019, 1, 55-64. [CrossRef]

55. Muślewski, $€$. The implementation of the fuzzy logic elements in the area of the transport system operation quality assessment. In Maritime Industry, Ocean Engineering and Coastal Resources, vol. 1, Maritime Transportation. Proceedings and Monographs in Engineering, Water and Earth Sciences; Soares, C.G., Kolev, P.N., Eds.; Taylor \& Francis Group, Balkema: London, UK; Leiden, The Netherlands; New York, NY, USA; Philadelphia, PA, USA; Singapore, 2007.

56. Asadia, A.; Zhangb, Y.; Mohammadi, H.; Khorand, H.; Rui, Z.; Hossein Doranehgard, M.; Bozorge, M. Combustion and emission characteristics of biomass derived biofuel, premixed in a diesel engine: A CFD study. Renew. Energy 2019, 138, 79-89. [CrossRef]

57. Masera, K.; Hossain, A. Biofuels and thermal barrier: A review on compression ignition engine performance, combustion and exhaust gas emission. J. Energy Inst. 2019, 92, 783-801. [CrossRef]

(C) 2019 by the authors. Licensee MDPI, Basel, Switzerland. This article is an open access article distributed under the terms and conditions of the Creative Commons Attribution (CC BY) license (http://creativecommons.org/licenses/by/4.0/). 